\title{
CORRUPÇÃO, GOVERNO E MERCADO: PERVERSIDADES DE RELAÇÕES CLIENTELÍSTICAS
}

CORRUPTION, GOVERNMENT AND MARKET: PERVERSIONS OF CLIENTELISTIC RELATIONS

CORRUPCIÓN, GOBIERNO Y MERCADO: PERVERSIDADES DE LAS RELACIONES CLIENTELARES

Rogério Gesta Leal ${ }^{1}$

Resumo: O presente trabalho pretende enfrentar o tema que envolve as relações entre corrupção, governo e mercado, e como elas retroalimentam cenários de clientelismo político perverso à Democracia - em especial no Brasil. A metodologia adotada foi a dedutiva, a partir de significativa abordagem teórica nacional e internacional sobre tais questões. Em termos de sínteses conclusivas, defende-se que o clientelismo político tem se prestado para reforçar os laços corruptivos entre mercado e governo, haja vista que opera a partir de uma lógica patrimonialista de poder e de seu exercício.

Palavras-chave: Corrupção - Mercado - Governo - Clientelismo - Democracia.

1 Doutor em Direito pela UFSC e UBA, 2000. Professor Titular da UNISC e da FMP, Santa Cruz do Sul-RS, Brasil. Desembargador do Tribunal de Justiça do Estado do Rio Grande do Sul, titular da Quarta Câmara Criminal, que julga crimes praticados por Prefeitos e Vereadores e Crimes contra a Administração Pública. E-mail: gestaleal@gmail.com. 
Abstract: This work addresses the topic that involves the relations between corruption, government and market, and how they reinforce scenarios of perverse political clientelism against Democracy, especially in Brazil. The deductive methodology was adopted, based on a significant national and international theoretical approach on such issues. In terms of conclusive syntheses, it is argued that political clientelism has been used to reinforce the corrupting links between market and government, since it operates from a patrimonialist logic of power and its exercise.

Key-words: Corruption - Market - Government - Clientelism Democracy.

Resumen: El presente trabajo pretende enfrentar el tema que involucra las relaciones entre corrupción, gobierno y mercado, y como las mismas retroalimentan escenarios de clientelismo político perverso en relación a la Democracia - en especial en Brasil. Se adoptó la metodología deductiva, a partir de un significativo abordaje teórico nacional e internacional sobre tales cuestiones. En términos de síntesis conclusivas, se defiende que el clientelismo político se ha prestado para reforzar los lazos corruptivos entre mercado y gobierno, considerando que opera a partir de una lógica patrimonialista de poder y de su ejercicio.

Palabras clave: Corrupción; Mercado; Gobierno; Clientelismo; Democracia.

\section{INTRODUÇÃO}

corrupção sempre surge em diversas formas e em múltiplos contextos
e relações, razões pelas quais, por vezes, é muito difícil defini-la e
identificá-la em termos absolutos. A despeito disto, podemos dizer que um dos efeitos nefastos da relação entre corrupção, governo e Mercado é o envolvimento de interesses e relações privadas contaminarem interesses e relações públicas - ou mesmo os efeitos desta lógica de relações perversas no âmbito das atividades econômicas do Mercado. 
Associado a isto está o tema do clientelismo político, fenômeno histórico que atinge países desenvolvidos e subdesenvolvidos, e que implica conceito de organização do Poder e de sua operacionalização altamente sofisticado sob o ponto de vista das relações sociais e institucionais contemporâneas.

Por tais razões, como objetivo geral e a partir de uma metodologia dedutiva, pretendemos demarcar algumas premissas que informam as perversas relações entre Mercado, Governo e Corrupção, para então tratar do problema que decorre destes cenários, a saber, como no Brasil o clientelismo político tem se configurado como ferramenta importante de retroalimentação da corrupção entre Mercado e Governo. Vamos sustentar como hipótese de resposta a este problema a necessidade de repensarmos estratégias de desarticulação da cultura de clientelismo político ora vigente no país, com a participação social, sob pena de termos aprofundamentos radicais no âmbito daquelas relações.

\section{IMPLICAÇÕES CORROSIVAS ENTRE CORRUPÇÃO,}

DEMOCRACIA E PODER

Quais são as implicações às Democracias contemporâneas, modo geral, das conexões corruptivas entre riqueza e poder? Quais as perspectivas de redução da corrupção e como esta tarefa está interligada com os amplos processos de democratização e mesmo com o papel do Estado?

Estes aspectos têm sido o foco de muitas pesquisas nos últimos tempos - basta vermos os trabalhos de Elliott ${ }^{2}$ e Heidenheimer ${ }^{3}$, todas fundadas em significativas estatísticas quantitativas e qualitativas de análises da corrupção. Mas muito deste trabalho implicitamente trata a corrupção de forma bastante similar, independentemente de onde ela ocorra, evidenciando elementos recorrentes nas suas causas e consequências, o que nem sempre autoriza o mesmo modelo explicativo sobre ela em todos os locais e em todos os níveis de gravidade.

2 ELLIOTT, Kimberly. Corruption and the Global Economy. Washington, D.C.: Institute for International Economics, 2004. Ver também o texto de MEDARD, Jean Franqois. Le rapport de clientele, du phenomene social a l'analyse politique. Revue Française de Science Politique, v. 26, 1978.

3 HEIDENHEIMER, Arnold J.; JOHNSTON, Michael, and LE VINE, Victor T. (Eds.). Political

Corruption: A Handbook. New Brunswick, NJ: Transaction Press, 2010. 
Entendemos, por outro lado, que os problemas de consolidação e liberalização da corrupção se manifestam em variáveis síndromes com diferentes implicações, o que demanda reconhecer que, se ações de corrupção estão enxertadas em amplos e profundos processos de múltiplas naturezas e performances, elas não podem ser abordadas como um problema discreto, por isto as análises sobre ela nos ajudam a compreender melhor os complexos problemas que enfrenta a Democracia contemporânea, em especial sua relação com o Mercado.

Enquanto a liberalização econômica global vai causando problemas a economias nacionais, notadamente os que envolvem a violação de Direitos e Garantias Fundamentais Individuais e Sociais, também tem provocado estímulos a comportamentos corruptivos em várias esferas públicas e privadas, o que contribui negativamente à consolidação e ao crescimento de regimes democráticos. Ou seja, instituições democráticas sólidas e competições de Mercado saudáveis (em especial preocupadas com aqueles Direitos Fundamentais referidos) podem contribuir em muito para a economia como para programas anticorrupção.

Frequentemente os países reduzem a corrupção no curso do enfrentamento de outros problemas de gestão pública, criminalizando condutas ilícitas contra a administração pública, legislação mais severa em relação a servidores públicos e do Mercado, mas em regra o fazem sem provocar mudanças em infraestruturas institucionais corroídas por práticas corruptivas.

A euforia que acompanhou a chamada Terceira Onda de transições à Democracia Liberal do final da década de 1970 e início da de 1980, muito bem trabalhadas por Alvin Toffler ${ }^{4}$ e Samuel P. Huntington ${ }^{5}$, por exemplo, já se preocupava em criar condições para que a corrupção não impactasse tanto os Mercados emergentes e promissores, como na América Latina, pois isto cedo ou tarde teria reflexos em todo o Ocidente. Em outras palavras, enquanto problemas econômicos

4 TOFFLER, Alvin. The third wave. New York: Bantam Books, 1980.

5 HUNTINGTON, Samuel Phillips. Political Order in Changing Societies. New Haven: Yale University Press, 1978. Apesar de ser um economilista Americano mais conservador, vale a leitura dos seus textos: (a) The Third Wave: Democratization in the Late Twentieth Century. Norman: University of Oklahoma Press, 1976, e (b) The Crisis of Democracy: On the Governability of Democracies. New York: New York University Press, 1976, este último escrito com Michel Crozier e Joji Watanuki, discutindo o tema da famosa Comissão Trilateral formada por países da Europa Central, Japão e Estados Unidos da América, em 1973. 
desde aqueles períodos ocupavam as manchetes dos meios de Comunicação de massas, modo geral, as questões políticas associadas a eles não recebiam o mesmo tratamento e protagonismo. ${ }^{6}$

Em face disto, novas instituições democráticas têm que ainda ganhar legitimidade ou demonstrar capacidade de governabilidade efetiva, colocando em suas agendas políticas e institucionais o enfrentamento da corrupção como menoscabo da Democracia, principalmente em face de que vários segmentos do Mercado ainda continuam a operar sob o manto da ilegalidade e da corrupção, a despeito das tardias, mas já existentes políticas públicas e privadas - assim como legislações - que se ocupam de controlá-los e puni-los. Aliás, como nos lembra O'Donnell:

... the institutional foundations of markets (capital and credit markets, solid currencies, courts, and transparent business practices) are weak. Political influence and economic activity are only partially institutionalized within official state and market frameworks; as a result, wealth, power, and connections between them are pursued through illicit channels, and create new, unaccountable institutions of their own. ${ }^{7}$

É curioso como os Estados Democráticos contemporâneos operam com a lógica formal - demarcada pela Constituição e legislação infraconstitucional - e a garantia dos Direitos Fundamentais e, ao mesmo tempo, mantêm (formal e materialmente) as matrizes institucionais e funcionais do Mercado como ele se encontra, isto é, espoliador e de exclusão social. A Sociedade, por sua vez, como portadora daqueles Direitos, ganha força em processos de reivindicação e cobrança por mais ética, transparência e responsabilidade, auxiliando os regimes democráticos a se instituírem e fortalecerem.

Estes estados de coisas revelam a existência de cenários públicos e privados com relações marcadas por níveis de tensionalidade e complexidade muito diferidos do que tivemos até há pouco, gerando desde o que podemos chamar de Democracias

6 Ver o texto de LINZ, Juan J., and STEPAN, Alfred. Problems of Democratic Transition and Consolidation: Southern Europe, South America, and Post-Communist Europe. Baltimore: Johns Hopkins University Press, 1996.

7 O'DONNELL, Guillermo. Delegative Democracy. Journal of Democracy, v. 5, nº1, January, 1994, pp. 55-69. Na mesma direção ver o texto de O'DONNELL, Guillermo. Disonancias. Críticas Democráticas a la Democracia. Buenos Aires: Prometeo, 2007. 
pobres em termos de civilidade (como a Índia), até regimes autoritários ricos (Kuwait e Singapura). ${ }^{8}$ Tais evidências vão de encontro às teses de que o crescimento precoce de Mercados se afigura como boa fundação à Democracia, mais do que Democracias precoces sem infraestrutura econômica, como quer Bardhan. ${ }^{9}$

Sinergias nestes campos minados, entendidas como eixo central em estratégias democráticas, foram durante muito tempo deixadas de lado por experiências políticas ocidentais, desconsiderando historicamentequeDemocraciase Mercados têm-se se suportado umas às outras (claro, com custos sociais imensos para os mais pobres), e isto porque eles têm sido modos de experiências predominantemente liberais, a despeito de assimétrica em várias formas, necessitando sempre de instituições fortes para proteger a expansão do protagonismo do Mercado e restringir seus excessos.

Desta forma, enquanto a referida Terceira Onda tem trazido boas oportunidades políticas e econômicas, assim como novas conexões entre riqueza e poder, muitas delas não têm dado retornos na equalização da relação entre crescimento econômico e desenvolvimento social sustentável, novamente obtendo mais êxito em suas demandas o Mercado. Para muitos cidadãos - talvez a maioria -, Democracia tem significado crescimento da pobreza e da insegurança em suas vidas pessoais, assim como ineficiência em termos de gestão pública social. Como nos diz Larry Diamond:

... democracy may be the most common form of government in the world, but outside of the wealthy industrialized nations it tends to be shallow, illiberal, and poorly institutionalized. If there are no immediate threats of democratic collapse in most of those countries, neither are there clear signs that democracy has become consolidated and stable, truly the only viable political system and method for the foreseeable future. In fact, of the more than 70 new democracies that have come into being since the start of the third wave, only a small number are generally considered to be deeply rooted and secure. The remainder appear for now condemned to remain democratic while they muddle through as unconsolidated democracies. ${ }^{10}$

8 Ver o texto de LESGART, Cecilia. Usos de la Transición a la Democracia. Ensayo, Ciencia y Política em la Década del '80. Rosario: Homo Sapiens, 2003.

9 PRANAB, Bardhan. Corruption and Development: A Review of Issues. Journal of Economic Literature, v.35, pp. 1320-1346, September, 2003.

10 DIAMOND, Larry. Introduction: In Search of Consolidation. In: DIAMOND, Larry; PLATTNER, Marc F.; CHU, Yan-han and TIEN, Hung-mao (Eds.). Consolidating the Third 
Esta tem sido a realidade brasileira dos últimos tempos, não somente pelos escândalos que temos presenciado envolvendo a Petrobrás e outros órgãos da administração pública, mas também e principalmente porque Poder Executivo e Poder Legislativo têm tido suas imagens e níveis de confiança social atingidos profundamente.

Por tais razões a corrupção tem se apresentado como particular problema à consolidação mais perene das Democracias, haja vista que perpassa Mercado, Administração Pública e mesmo a Sociedade (quando é tolerante ou indiferente). Ainda para dificultar o controle e enfrentamento desta patologia, frequentemente ela se encontra profundamente entranhada nas mais diversas relações institucionais e intersubjetivas, envolvendo tantas pessoas (físicas e jurídicas), que por vezes é complicado identificar com precisão e de forma ágil os verdadeiros responsáveis - e geralmente são vários.

Por outro lado, instituições políticas e Mercado fracos sob o ponto de vista ético e moral, sem controle social e instrumentos normativos adequados, auxiliam práticas ilícitas a florescer; por vezes estes sujeitos cooptados pela corrupção criam redes políticas e burocráticas fortemente organizadas, protegendo-se inclusive através da violência, se necessário. ${ }^{11}$ Isto tudo impede processos socialmente responsáveis de atendimento de demandas comunitárias, não por ausência de recursos públicos privados, mas pelo fato de que eles são desviados de suas finalidades originárias e vinculadas e, assim sendo, provocam-se quebras de fidúcia e credibilidade das instituições envolvidas nestes arranjos corruptivos.

Agora atenção: a corrupção não pode ser tomada como responsável por tudo o que existe de ruim nas relações de Mercado e de Governo, tampouco pela destruição do que há de positivo nestes âmbitos. Temos que compreender que

Wave Democracies: Themes and Perspectives. Baltimore: Johns Hopkins University Press, 1997, p. 15.

11 Neste sentido ver o interessante trabalho de SPALDING, Andrew Brady. Unwitting sanctions: understanding antibribery legislation as economic sanctions against emerging markets. Disponível em: <http://www.floridalawreview.com/wp-content/uploads/2010/01/ Spalding_BOOK.pdf >. Acesso em: 15 maio 2017. Na mesma direção ver o excelente texto de NICHOLS, Philip M. The Neomercantilist Fallacy and the contextual reality of the foreign corrupt practices act. Disponível em: <http://harvardjol.com/wp-content/ uploads/2016/02/HLL108_crop.pdf>. Acesso em: 15 maio 2017. 
fenômenos como a corrupção têm várias causas (e consequências), por isto é considerada por alguns de seus estudiosos como uma terrível doença (dread desise), e por causa disto, "benefits powerful interests, while weakening potential competitors and disrupting accountability, corruption can be a durable and longstanding state of affairs". ${ }^{12}$

Por certo que a corrupção envolve, historicamente, o abuso de recursos públicos para benefícios privados, mas nos dias atuais ela se presta para demarcar várias outras relações que não incluem somente agentes públicos, mas atores do Mercado das relações econômicas privadas, fazendo destes protagonistas peças centrais nos nefastos efeitos gerados que a todos alcança.

\section{PERVERSAS RELAÇÕES ENTRE MERCADO E GOVERNO:}

PREMISSAS PRELIMINARES

Sempre é bom lembrar que o termo corrupção vem do verbo latino rumpere, que significa quebrar, que alguma coisa foi quebrada. Esta coisa pode ser um código moral ou social, ou, mais frequentemente, regras administrativas do setor público (e privado). Para que estes elementos sejam quebrados, tais códigos ou regras têm de ser precisos e transparentes. Outro elemento geralmente presente em atos de corrupção é o que diz respeito ao fato de que o(s) agente(s) que dão causa a esta ruptura tenham algum tipo de benefício para eles próprios, sua família, seus amigos, seu Partido Político, ou outro grupo institucional ou econômico importante. É comum ainda que estes benefícios derivados dos atos corruptivos sejam vistos como diretamente decorrentes deles, mesmo que mascarados por aparências de legalidades formais.

Em face de tais ponderações, tem-se convencionado que deve haver evidências muito claras de que regras ou códigos foram quebrados por conta de atos corruptivos, o que requer estejam estas normas estabelecidas com clareza incontestável, não deixando dúvidas sobre seus significados e alcances, tampouco

12 FISHMAN, Raymond and MIGUEL, Edward. Economic Gangsters: Corruption, Violence and the Poverty of Nations. Princeton, NJ: Princeton University Press, 2008, p.39. 
permitindo que o poder discricionário/arbitrário dos agentes púbicos estabeleça atribuições de sentido manipulativas a favor da corrupção. ${ }^{13}$

Quando códigos de conduta e regras de procedimentos éticos no trato de interesses públicos indisponíveis não são claros ou se prestam a ser manipulados por burocratas de órgãos públicos, aí temos problemas à contenção da corrupção. Por exemplo, em alguns países, como adverte Manuel Guerreiro, a legislação tem permitido que a avaliação para incentivos fiscais ou licenças de importação esteja sob o crivo exclusivo de agentes públicos, cabendo a estes, em última instância, decidir quem recebe ou não tais incentivos ou licenças, o que significa outorgar o poder de definir o que é essencial ou necessário para o país em termos de investimentos fomentados por tais benefícios legais. Estes agentes públicos se apresentam, então, como os intérpretes originais do que estes termos legais querem dizer. Assim, eles se encontram no monopólio da gestão pública que pode garantir ou denegar incentivos ou licenças, os quais não podem ser obtidos por outras fontes. ${ }^{14}$

Durante muitos anos tem havido controvérsias as mais diversas entre economistas e cientistas políticos sobre se políticas econômicas deveriam ser guiadas por regras rígidas ou se elas deveriam restar submetidas a deliberações mais discricionárias do setor competente. Este debate, todavia, revelou que decisões mais discricionárias poderiam ser utilizadas muito mais em favor de interesses privados do que públicos, tornando-se evidente que a melhor política preventiva à corrupção seria a de criar normas rígidas e precisas sobre a gestão de interesses públicos - ou que tivessem impacto sobre eles. ${ }^{15}$

Por outro lado, podemos pensar que é precisamente o excesso de regras que criam férteis campos à corrupção. Ou seja, se leis são tão rígidas, elas podem 13 Ver o texto de ABED, George T. \& DAVOODI, Hamid R. Corruption, Structural Reforms, and Economic Performance in the Transition Economies. IMF Working Paper no 00/132, 2000.

14 Ver o texto de GUERRERO, Manuel Alejandro \& Eduardo RODRIGUEZ-OREGGIA. On the Individual Decision to Commit Corruption: A Methodological Complement. Journal of Economic Behavior \& Organization, v. 65(2), p. 357-372, 2008.

15 Neste sentido o texto de HALIM, Nafisa. Testing Alternative Theories of Bureaucratic Corruption in Less Developed Countries. Social Science Quarterly, v. 89(1), p. 236-257, 2008. No mesmo sentido, HALL, Kath. Strategic Privatisation of Transnational Anti-Corruption Regulation. Australian Journal of Corporate Law, v. 28, p. 60-71, 2013. Sabemos também que algumas normas são criadas para o efeito de dar a determinados agentes públicos poderes exagerados para fins de cometerem atos de corrupção. 
criar obstáculos para o bom funcionamento da economia ou de organizações particulares, gerando igualmente cenários favoráveis à corrupção.

Quando relações institucionais (principalmente públicas) tendem a serfechadas e pessoais, pode ser difícil estabelecer links diretos entre atos que poderiam caracterizar a corrupção e os pagamentos particulares para obtê-los. Um empregado que usa sua posição institucional e oficial para favorecer conhecidos - no sentido de ajudar a obter valiosas licenças públicas, ou contrato com o governo, ou mesmo emprego público -, pode ser compensado com imediato e explícito pagamento de propina.

Alternativamente, agentes públicos podem ser compensados muito tempo depois com generosos presentes, por exemplo, para seus filhos quando casam, ou com um bom emprego para eles quando completam seus estudos. Em outras palavras, não existe mais, em termos de corrupção, relação direta, explícita e imediata com relação à compensação decorrente do favor corrupto. Aliás, propositadamente estamos falando de compensação porque a ideia de pagamento restringe muito as possibilidades da contrapartida à corrupção à forma monetária, enquanto que os favores que servem para o mesmo fim podem ser múltiplos (no âmbito do nepotismo, de favores sexuais, presentes, troca de informações, etc.). ${ }^{16}$ Isto também coloca em xeque não somente a moeda contemporânea da corrupção, mas as maneiras tradicionais de combatê-la.

Vejamos ainda que, sendo o pagamento na forma da compensação, e ele se protraindo no tempo, quando ocorre (às vezes meses ou anos depois), pode aparecer completamente desconectado com os favores intercambiados corruptiva e preteritamente. Como nos dizem Andvig e Moene: "in many cases, the "corrupted" and the 'corruptor' may never even have discussed the payment. It would simply be understood that a favor granted today creates a presumption or even an obligation for a reciprocal favor tomorrow". ${ }^{17}$

16 Ver a matéria jornalística no site: Disponível em: <http://g1.globo.com/fantastico/videos/t/ edicoes /v/desonestidade-troca-de-favores-tramoias-conheca-o-retrato-da-corrupcao-nobrasil/3402345/>. Acesso em: 10 abr. 2017, onde se evidencia de forma clara a forma de troca de favores que marca a política nacional.

17 ANDVIG, J.C. § MOENE K.O. How Corruption May Corrupt. Journal of Economic Behavior and Organization, no 13, 1990, p.69. Ver também o texto de BARDHAN, Pranab. Corruption and Development: A Review of Issues. Journal of Economic Literature n035: 1320-46, 1997. 
Em algumas Sociedades, o Mercado de Sombras envolvendo aquela troca de favores se retroalimenta com as demandas e as ofertas corruptivas e seus, por vezes, implícitos preços. ${ }^{18}$ Este Mercado geralmente não se utiliza de dinheiro em espécie, mas negocia com o que poderíamos considerar o equivalente ao que na experiência da América do Norte chamamos IOUs, abreviação da expressão eu te devo, consistindo, geralmente, em documento informal que reconhece alguma dívida. Um IOU difere de qualquer outro tradicional título de crédito na medida em que não é um instrumento negociável e não especifica prazos de reembolso, mas apenas identifica o devedor, o montante devido e, às vezes, o credor. Tais documentos podem ser assinados ou possuir marcas distintivas ou desenhos para garantir a autenticidade, e em alguns casos podem ser resgatáveis para um produto ou serviço específico, em vez de uma quantidade de moeda. ${ }^{19}$ Ou seja, com tal flexibilização inclusive da moeda de negócios hoje, tudo fica mais fácil para a corrupção e suas formas de consecução.

Em tais cenários complexos, os preços implícitos por favores prestados (principalmente os compensados futuramente) vão se estabilizando como opção de negócios, o que dificulta ainda mais a separação entre genuínos e filantropos favores gratuitos prestados de forma não ilícita, daqueles que são efetivamente decorrentes de propina ou outra vantagem ilícita, o que igualmente dificulta a clara identificação da responsabilidade por ato corruptivo.

É possível, pois, afirmarmos que, em Sociedades nas quais relações sociais e institucionais são contaminadas demasiadamente por vínculos de associação familiar, afetiva ou de interesses escusos (como o Brasil), a expectativa de que o interesse e espaço público não sejam afetados de alguma maneira chega a ser romântica. Nestas Sociedades, o tipo de burocracia estatal racional e

18 Este conceito de Mercado de Sombras é muito interessante e vem desenvolvido no texto de BHATTACHARYYA, S. § HODLER, R. Media freedom and democracy in the fight against corruption. In: European Journal of Political Economy n039, 2012, pp.13-24. Ver também nosso livro LEAL, Rogério Gesta. A Responsabilidade penal do patrimônio ilícito como ferramenta de enfrentamento da criminalidade. Porto Alegre: FMP, 2017. Disponível em: <http://www.fmp.edu.br/servicos/285/publicacoes/>. Acesso em 15 mai. 2017.

19 MCLEAY, Michael, RADIA, Amar and THOMAS, Ryland. Money in the modern economy: an introduction. Bank's Monetary Analysis Directorate. Disponível em: <http://www. bankofengland.co.uk/publications/Documents/quarterlybulletin/2014/qb14q1prereleasemoneyintro.pdf>. Acesso em: 10 abr. 2017. 
ideal advogada por Max Weber tem se afigurado de difícil instalação. ${ }^{20} \mathrm{E}$ entendamos defitivamente como ideal de gestão pública por burocracias racionais à moda Weber, o que nos diz Kalberg: "In the Weberian ideal, bureaucrats would work within a set of principles in which there is no place for personal relations or cronyism and, above all, there would be no confusion of public with private interests" ${ }^{21}$

A vida no mundo real de que estamos falando, todavia, é possível que seja diferente!? Já há muito tempo tem se aceitado amplamente normas sociais que frequentemente operam como guias de comportamentos específicos do que normas importadas baseadas em disposições impessoais e princípios universais. Quando esta realidade é ignorada, desapontamentos decorrentes são muito comuns. Isto explica por que algumas reformas impostas em países desenvolvidos, promovidas por consultores estrangeiros, as quais podem demandar ou assumir relações mais pessoais, não resistem ao teste do tempo e da eficiência para os fins originariamente almejados.

Nestas Sociedades, o custo do papel corretivo do governo no Mercado tem aumentado consideravelmente. Relações econômicas no setor privado também são afetadas, tornando mais difícil o regular e lícito funcionamento da economia de Mercado.22 É possível, em face do exposto, sustentar que as relações pessoais que venham a se estabelecer entre setor público e indivíduos que mantêm relações com ele possam caracterizar riscos corruptivos, mas tão só não é o bastante para compreender este fenômeno - aliás, como já tivemos oportunidade de dizer ${ }^{23}$-,

20 Ver o texto de WEBER, Max. La institución estatal racional y los partidos políticos y parlamentos modernos (Sociologia del Estado). Economia y Sociedad. México: Fondo de Cultura Economica, 1969, vol. II, Capítulo IX, ítem IX, p. 1057 e seguintes.

21 KALBERG, Stephen. Max Weber's Types of Rationality: Cornerstones for the Analysis of Rationalization Processes in History. The American Journal of Sociology, Vol. 85, n5, p.1152. Chicago: The University of Chicago Press, 1980. Disponível em: <http://www.jstor. org/stable/2778894>. Acesso em 10 abr. 2017.

22 Ver o texto de DRURY, Alfred Cooper; KRIECKHAUS, Jonathan § LUSZTIG, Michael. Corruption, Democracy, and Economic Growth. In: International Political Science Review

/ Revue internationale de science politique, Vol.27, No. 2 (Apr., 2006), pp.121-136. Acesso pelo sítio http://www.jstor.org/stable/20445044, em 17/04/2017. Alfred Cooper dirige a importante Foreign Policy Analysis Review, que em seu volume de Abril/2017 traz dois artigos sobre o Brasil. Ver no sítio: https://academic.oup.com/fpa/issue/13/2. Acesso em: $17 / 04 / 2017$.

23 Ver nosso LEAL, Rogério Gesta. Patologias Corruptivas nas relações entre Estado, Administração Pública e Sociedade: causas, consequências e tratamentos. Santa Cruz 
porque falta aqui levar em conta que tais relações simplesmente refletem normas morais e sociais diferentes no espaço e no tempo.

A verdade é que os cenários que fazem a corrupção possível são muitos, desde: (i) a administração de regulações governamentais, tais como as que envolvem as limitações urbanísticas para construção civil, a ocupação fundiária e a emissão de licenças e as permissões para tanto (um dos âmbitos mais expostos à corrupção em países hiper-habitados é o da ocupação urbana ${ }^{24}$ ); (ii) a manipulação de multas por suposta ou efetiva violação de normas legais; (iii) a ausência ou o deficitário controle das licitações e contratos públicos; (iv) a ausência ou o deficitário controle de investimentos públicos, e mesmo da equação entre receitas e despesas públicas, haja vista o insulamento burocrático que se tornou a constituição, a execução e a avaliação dos orçamentos públicos como peças administrativas e contábeis, e por isto muitas vezes distanciadas do controle social e jurisdicional; (v) a manipulação de subsídios creditícios pela via de fomento público bancário sem controles maiores; (vi) violações dos sistemas previdenciário e de saúde pública, pela via de fraude de benefícios, aposentadorias, tratamentos e intervenções médicas, fornecimento de medicamentos.

Diante de tantas possibilidades, por óbvio que as ferramentas de controle preventivo e curativo devem ser mais eficientes e amplas, o que não tem se evidenciado ao menos no Brasil nos últimos tempos. Por tais razões, o amplo diagnóstico destes elementos é fundamental à formatação de políticas públicas eficazes de enfrentamento da corrupção.

Agora, quando, por exemplo, servidores públicos se apropriam, para uso pessoal ilícito, dos instrumentos que o Estado possui para influenciar a economia e corrigir os resultados detrimentosos do Mercado privado, eles reduzem o poder do Estado e sua possibilidade para alcançar os objetivos sociais que têm em face de suas obrigações e papel na Democracia contemporânea.

do Sul: Edunisc, 2013. Ver também o já clássico texto de POLÁNYI, Karl. A grande transformação: as origens da nossa época. Rio de Janeiro: Campus, 1980.

24 Veja-se o interessante texto de BAALI, Fuad. Society, State and Urbanism: ibn Khaldun's socilogical thought. Albany: State University New York Press, 1987. Ver igualmente o excelente livro BASALDUA, Juan Ignacio Echano (Org.). Corrupción y Urbanismo. Cuadernos Penales José María Lidón, vol.5. Bilbao: Universidad de Deusto, 2008. 


\section{CONSIDERAÇÕES FINAIS: O CLIENTELISMO COMO FACILITADOR DAS RELAÇÕES CORRUPTIVAS ENTRE MERCADO E GOVERNO}

Queremos sustentar, a partir do todo exposto, que as relações entre corrupção, governo e mercado podem ter forte influência - em suas causas e consequências - no modelo de formatação política do Estado e da Sociedade em termos históricos e, no caso brasileiro, seguramente em face das tradições clientelistas que configuraram estas relações.

O tema do clientelismo vem sendo explorado há muito tempo pela ciência política e pela sociologia como categoria que se ocupa de avaliar os desajustes entre o desenvolvimento econômico-social e a falta de estabilidade das instituições políticas. ${ }^{25} \mathrm{Na}$ percepção correta de Avelino Filho, a política clientelista atual vem marcada pelo fato de que suas relações tendem a ser muito mais frágeis, já que mais instrumentais. "Ela sobrevive a partir da sua capacidade de substituir os antigos laços de lealdade pessoal pela oferta de benefícios materiais, os mais individuais possíveis, de maneira a evitar conflitos e maximizar o seu arco de influência eleitoral". ${ }^{26}$

Não temos tempo para ingressar aqui no debate sobre os efeitos negativos que as relações históricas de deficits de representatividade política da Sociedade - em especial a brasileira - têm operado a favor da formatação de cenários clientelistas na política e sua operacionalização ${ }^{27}$, mas queremos tão somente 25 Ver o clássico texto de SCHMIDT, S. W; SCOTT, J. C.; LANDE, C. and GUASTI, L. Friends, Followers and Factions: A Reader in Political Clientelism. Berkeley: University of California Press, 1977.

26 AVELINO FILHO, George. Clientelismo e política no Brasil: revisitando velhos problemas. Novos Estudos CEBRAP, n038, março 1994, p.227. Todavia, adverte o autor para o fato de que o funcionamento de uma suposta institucionalidade clientelista exige que se ofereçam garantias mínimas de continuidade de maneira a gerar alguma certeza, alongar as expectativas e ordenar as demandas. Se o clientelismo fosse dotado apenas de uma lógica desagregadora e particularista, e essa lógica fosse levada até o fim, ele deixaria de existir. Pois, não há como ordenar apenas interesses específicos e urgentes, indivíduos cínicos e egoístas. A confiança e a cooperação seriam impossíveis e o mundo, incerto e hobbesiano. (p.228).

27 Para o aprofundamento deste debate, ver os trabalhos de: (i) DUARTE, Nestor. A ordem privada e a organização política nacional. São Paulo: Companhia Editora Nacional, 1939; (ii) CARVALHO, José Murilo de. Mandonismo, Coronelismo, Clientelismo: uma discussão conceitual. DADOS - Revista de Ciências Sociais, Rio de Janeiro, v. 40, n. 2, 
identificar alguns pressupostos constitutivos destas relações que permanecem até hoje fomentando situações corruptivas as mais diversas.

Historicamente o Brasil contou (e conta) com práticas políticas por vezes autoritárias, por vezes paternalistas e assistencialistas, protagonizando as instituições políticas em geral - e os partidos políticos no particular-, a privatização dos espaços públicos, transmutando interesses privados e corporativos em objetivos e prioridades nacionais, principalmente vinculados ao Mercado e à concentração de capital, renda e riqueza. ${ }^{28}$

Werneck Vianna lembra que autores como Simon Schwartzman sustentavam, à moda Weber, que o Brasil sempre esteve imerso em um

... sistema político de cooptação sobreposto ao de representação, uma sociedade estamental igualmente sobreposta à estrutura de classes, o primado do Direito Administrativo sobre o Direito Civil, a forma de domínio patrimonial-burocrática e o indivíduo como um ser desprovido de iniciativa e sem direitos diante do Estado. ${ }^{29}$

Maria Sylvia de Carvalho Fraga, com quem concordamos, avançando para além do patrimonialismo de vertente weberiana, defende a tese de que foi a pobreza da agência estatal brasileira e de sua matriz de gestão pública que teria dado como resultado não desejado a fusão entre o público e o privado, permitindo, assim, que o exercício do poder originário do cargo público pudesse ser traduzido na busca de fins estritamente particulares. ${ }^{30}$

p. 241; (iii) GRAHAM, Richard. Clientelismo e política no Brasil do século XIX. Rio de Janeiro: Editora UFRJ, 1997; (iv) CLAPHAM, Christopher. Clientelism and the State. In: CLAPHAM, Christopher (Ed.). Private Patronage and Public Power. Political Clientelism in the Modern State. London: Palgrave Macmillan, 1982; (iv) DEZALAY, Yves § GARTH, Bryant. The Internationalization of Palace Wars: Lawyers, Economists and the Contest to Transform Latin American States. Chicago: University of Chicago Press, 2002.

28 Ver os textos de: (i) BORON, Atilio. Estado, Capitalismo e Democracia na América Latina. São Paulo, Paz e Terra, 1999; (ii) DUPAS, Gilberto. Tensões contemporâneas entre o público e o privado. São Paulo: Paz e Terra. 2005; (iii) MÉSZAROS, István. Para além do Capital. São Paulo: Boitempo Editorial, 2002; (iv) FERNANDES, Florestan. Nova República? Rio de Janeiro: Zahar, 1985. Ainda em vertente Weberiana, ver o trabalho ALONSO, Angela. Império da Patronagem. In: Novos Estudos CEBRAP, São Paulo (49), novembro de 1997; (iii) FAORO, Raymundo. Os Donos do Poder. Rio de Janeiro: Globo, 2012.

29 VIANNA, Luiz Werneck. Weber e interpretação do Brasil. Novos Estudos CEBRAP, São Paulo (53), março de 1999, p.35. Ver igualmente o texto de SCHWARTZMAN, Simon. Bases do Autoritarismo Brasileiro. São Paulo: Campus, 1988.

30 FRANCO, Maria Sylvia de Carvalho. Homens Livres na Ordem Escravocrata. São Paulo: Unesp, 1974, p.27. Ver também o texto de GRAHAM, Richard. Clientelismo e política no Brasil do século XIX. Rio de Janeiro: Editora UFRJ, 1997. 
De qualquer sorte, independentemente das matrizes políticas e sociológicas que venhamos a adotar para compreender as causas dos processos antidemocráticos de constituição e desenvolvimento do espaço público no Brasil, e como este se vê progressivamente exposto a várias formas de apropriação corruptiva (pelo Mercado, por Partidos Políticos fisiológicos, porfacções religiosas, etc.), é certo que o afastamento destes cenários da Sociedade e sua Cidadania como sujeitos que deveriam exercitar seus direitos fundamentais de participação política só tem contribuído para o agravamento das crises institucionais que estamos vivendo. Vai nesta direção a reflexão de Farias:

i) o clientelismo é a apropriação privada da coisa pública; ii) a barganha do voto representa uma corrupção da democracia. As razões apresentadas para o desvirtuamento da democracia pelo clientelismo normalmente são: a pobreza, a ignorância, a herança de um passado pré-moderno. Acredita-se que, com a consolidação da democracia, o clientelismo poderá ser reduzido a um patamar insignificante. ${ }^{31}$

Em verdade, a lógica hegemônica da política no Estado Democrático de Direito brasileiro ainda hoje não é a da participação cívica da cidadania nos negócios públicos cotidianamente, imperando a presença de notáveis para o exercício deste mister, seja na esfera legislativa (com Partidos Políticos e Parlamentares muitos divorciados de compromissos públicos), seja no Poder Executivo, com mandatários que se apossam dos órgãos públicos, utilizando-os como patrimônio pessoal seu e disponível, direcionando-os à persecução de fins ilícitos ou distintos das demandas sociais efetivas. ${ }^{32}$

Esta cultura da política tem feito com que o clientelismo atual seja mais competitivo que o de outros tempos (período de Getúlio Vargas, no Brasil), e suas relações tendem a ser mais débeis, eis que incisivamente instrumentais, fortalecendose a partir da capacidade de substituir os antigos laços de lealdade pessoal pela

31 FARIAS, Francisco Pereira de. Clientelismo e democracia capitalista: elementos para uma abordagem alternativa. Revista de Sociologia e Política, n¹5. Curitiba: Universidade Federal do Paraná, 2000, p.49.

32 Veja-se os interessantes textos de: (i) PORTA, D. D. Introdução à Ciência Política. Lisboa: Editorial Estampa, 2003; (ii) TEIXEIRA, M. J. \& REVEZ, A. M. Velhos e Novos Actores Políticos. Partidos e Movimentos Sociais. Lisboa: Universidade Aberta, 2005; (iii) ELIAS, Norbert A Sociedade de Corte: investigação sobre a sociologia da realeza e da aristocracia de corte. Rio de Janeiro: Jorge Zahar, 2001; (iv) CARVALHO, José Murilo de. A Construção da Ordem: a elite política imperial. Teatro das Sombras: a política imperial. Rio de Janeiro: Civilização Brasileira, 2003. 
oferta de benefícios materiais, os mais individuais possíveis, de maneira a evitar conflitos e maximizar o âmbito de influência eleitoral, de governabilidade e mesmo institucional. ${ }^{33} \mathrm{E}$ é este plano da institucionalidade do clientelismo que tem trazido, em escalas nunca antes vistas, processos de radicalização endêmica da corrupção no Estado, Mercado e na Sociedade contemporâneos (em especial no Brasil).

Isto ocorre porque o funcionamento desta institucionalidade clientelista exige que se ofereçam garantias mínimas de continuidade das relações perversas e ilícitas que o geraram, e os fins a que se destinam, de maneira a assegurar minimamente perspectivas de estabilidade dos compromissos intercambiados, pois também aqui estão presentes estruturados investimentos empresariais e comerciais - alguns de médio e longo prazo. ${ }^{34}$

Vejamos como exemplo o caso do escândalo da Petrobrás, que conta não só com o enriquecimento ilícito de políticos tradicionais e notáveis do Estado, mas com imensos investimentos empresariais (no caso, a Odebrecht) em demandas superfaturadas, nacionais e internacionais, de infraestrutura, serviços e obras públicas indispensáveis ao Mercado e à própria Sociedade. Aliás, não temos visto muito o questionamento sobre a seguinte questão: se a Odebrecht pagou bilhões de reais em propina a vários políticos brasileiros e internacionais, e são estes valores que têm vindo a público, quanto será que ela faturou líquida e ilicitamente neste tempo todo? Quando vai se apurar isto?

São todas questões que ainda merecerão em muito nossa atenção.

\section{REFERÊNCIAS DAS FONTES CITADAS}

ABED, George T. \& DAVOODI, Hamid R. Corruption, Structural Reforms, and Economic Performance in the Transition Economies. IMF Working Paper, n 132, 2000.

33 Conforme ACUÑA CHAVERRI, Iván A. Elementos conceptuales del clientelismo político y sus repercusiones en la democracia. Revista Reflexiones, no 88.2, 2009, p. 27-36. Na mesma direção o texto de GAY, Robert. Entre el clientelismo y el universalismo, reflexiones sobre la política popular em el Brasil urbano. In: AUYERO, Javier (comp.). ¿Favores por votos? Estudios sobre clientelismo político contemporáneo. Buenos Aires: Losada, 1997, pp.67-92. No Brasil ver o texto de SOUZA, Ricardo Luiz. Positivismo, Monarquismo, Autoritarismo, Coronelismo, Populismo - Reflexões Sobre a Política e História. Curitiba: Juruá, 2010.

34 Ver os textos de: (i) NUNES, Edson. A gramática política no Brasil. Rio de Janeiro: Jorge Zahar, 1999; (ii) BAHIA, Luiz Henrique Nunes. O poder do clientelismo: raízes e fundamentos da troca política. Rio de Janeiro: Renovar, 2003. 
ACUÑA CHAVERRI, Iván A. Elementos conceptuales del clientelismo político y sus repercusiones en la democracia. Revista Reflexiones, n 88.2, 2009.

ALONSO, Angela. Império da Patronagem. São Paulo: Novos Estudos CEBRAP, v. 49, novembro de 1997.

ANDVIG, J.C. § MOENE K.O. How Corruption May Corrupt. Journal of Economic Behavior and Organization, $n^{\circ} 13,1990$.

AVELINO FILHO, George. Clientelismo e política no Brasil: revisitando velhos problemas. Novos Estudos CEBRAP, n³8, março 1994.

BAALI, Fuad. Society, State and Urbanism: ibn Khaldun's socilogical thought. Albany: State University New York Press, 1987.

BAHIA, Luiz Henrique Nunes. O poder do clientelismo: raízes e fundamentos da troca política. Rio de Janeiro: Renovar, 2003.

BARDHAN, Pranab. Corruption and Development: A Review of Issues. Journal of Economic Literature, n³5, 1997.

BASALDUA, Juan Ignacio Echano (Org.). Corrupción y Urbanismo. Cuadernos Penales José María Lidón, vol.5. Bilbao: Universidad de Deusto, 2008.

BHATTACHARYYA, S. § HODLER, R. Media freedom and democracy in the fight against corruption. European Journal of Political Economy, n³9, 2012.

BORON, Atilio. Estado, Capitalismo e Democracia na América Latina. São Paulo: Paz e Terra, 1999.

CARRANZA, Mario E. Rising Regional Powers and Foreign Policy Analysis. Disponível em: <https://academic.oup.com/fpa/issue/13/2>. Acesso em 17 abr. 2017.

CARVALHO, José Murilo de. A Construção da Ordem: a elite política imperial. Teatro das Sombras: a política imperial. Rio de Janeiro: Civilização Brasileira, 2003.

CARVALHO, José Murilo de. Mandonismo, Coronelismo, Clientelismo: uma discussão conceitual. In: DADOS - Revista de Ciências Sociais, Rio de Janeiro, v. 40, n²， 2005.

CLAPHAM, Christopher. Clientelism and the State. In: CLAPHAM, Christopher (Ed.). Private Patronage and Public Power. Political Clientelism in the Modern State. London: Palgrave Macmillan, 1982.

CROZIER, Michel; WATANUKI, Joji. The Crisis of Democracy: On the Governability of Democracies. New York: New York University Press, 1976. 
DEZALAY, Yves § GARTH, Bryant. The Internationalization of Palace Wars: Lawyers, Economists and the Contest to Transform Latin American States. Chicago: University of Chicago Press, 2002.

DIAMOND, Larry. Introduction:In Search of Consolidation. In: DIAMOND, Larry; PLATTNER, Marc F.; CHU, Yan-han and TIEN, Hung-mao (Eds.). Consolidating the Third Wave Democracies: Themes and Perspectives. Baltimore: Johns Hopkins University Press, 1997.

DIAMOND, Larry; PLATTNER, Marc F.; CHU, Yan-han and TIEN, Hung-mao (Eds.). The Third Wave: Democratization in the Late Twentieth Century. Norman: University of Oklahoma Press, 1976.

DRURY, Alfred Cooper; KRIECKHAUS, Jonathan § LUSZTIG, Michael. Corruption, Democracy, and Economic Growth. International Political Science Review/Revue internationale de science politique, v.27, n. 2, 2006. Disponível em: <http://www.jstor.org/stable/20445044>. Acesso em: 17 abr. 2017.

DUARTE, Nestor. A ordem privada e a organização política nacional. São Paulo: Companhia Editora Nacional, 1939.

DUPAS, Gilberto. Tensões contemporâneas entre o público e o privado. São Paulo: Paz e Terra. 2005.

ELIAS, Norbert. A Sociedade de Corte: investigação sobre a sociologia da realeza e da aristocracia de corte. Rio de Janeiro: Jorge Zahar, 2001.

ELLIOTT, Kimberly. Corruption and the Global Economy. Washington, D.C.: Institute for International Economics, 2004.

FAORO, Raymundo. Os Donos do Poder. Rio de Janeiro: Globo, 2012.

FARIAS, Francisco Pereira de. Clientelismo e democracia capitalista: elementos para uma abordagem alternativa. Revista de Sociologia e Política, $n^{\circ} 15$. Curitiba: Universidade Federal do Paraná, 2000.

FERNANDES, Florestan. Nova República? Rio de Janeiro: Zahar, 1985.

FISHMAN, Raymond and MIGUEL, Edward. Economic Gangsters: Corruption, Violence and the Poverty of Nations. Princeton, NJ: Princeton University Press, 2008. 
FRANCO, Maria Sylvia de Carvalho. Homens Livres na Ordem Escravocrata. São Paulo: Unesp, 1974.

GAY, Robert. Entre el clientelismo y el universalismo, reflexiones sobre la política popular em el Brasil urbano. In: AUYERO, Javier (comp.). ¿Favores por votos? Estudios sobre clientelismo político contemporáneo. Buenos Aires: Losada, 1997.

GLOBO.COM. Desonestidade, troca de favores, tramoias: conheça o retrato da corrupção no Brasil. Disponível em: <HTTP://g1.globo.com/fantastico/videos/t/ edicoes/v/desonestidadetroca-de-favores-tramoias-conheca-o-retrato-da-corrupcao-no-brasil/3402345/>. Acesso em: 10 abr. 2017.

GRAHAM, Richard. Clientelismo e política no Brasil do século XIX. Rio de Janeiro: Editora UFRJ, 1997.

GUERRERO, Manuel Alejandro \& Eduardo RODRIGUEZ-OREGGIA. On the Individual Decision to Commit Corruption: A Methodological Complement. Journal of Economic Behavior \& Organization, v. 65(2), 2008.

HALIM, Nafisa. Testing Alternative Theories of Bureaucratic Corruption in Less Developed Countries. Social Science Quarterly, v. 89(1), 2008.

HALL, Kath. Strategic Privatisation of Transnational Anti-Corruption Regulation. Australian Journal of Corporate Law 28, 2013.

HEIDENHEIMER, Arnold J.; JOHNSTON, Michael, and LE VINE, Victor T. (Eds.). Political Corruption: A Handbook. New Brunswick, NJ: Transaction Press, 2010.

HUNTINGTON, Samuel Phillips. Political Order in Changing Societies. New Haven: Yale University Press, 1978.

KALBERG, Stephen. Max Weber's Types of Rationality: Cornerstones for the Analysis of Rationalization Processes in History. The American Journal of Sociology, v. 85, n5, Chicago: The University of Chicago Press, 1980. Disponível em <http://www.jstor.org/stable/2778894>. Acesso em 100 abr. 2017.

LEAL, Rogério Gesta. Patologias Corruptivas nas relações entre Estado, Administração Pública e Sociedade: causas, consequências e tratamentos. Santa Cruz do Sul: Edunisc, 2013.

LEAL, Rogério Gesta. A Responsabilidade penal do patrimônio ilícito como ferramenta de enfrentamento da criminalidade. Porto Alegre: FMP, 2017. Disponível em: <http://www. fmp.edu.br/servicos/285/publicacoes/>. Acesso em: 16 abr. 2017. 
LESGART, Cecilia. Usos de la Transición a la Democracia. Ensayo, Ciencia y Política em la Década del '80. Rosario: Homo Sapiens, 2003.

LINZ, Juan J., and STEPAN, Alfred. Problems of Democratic Transition and Consolidation: Southern Europe, South America, and Post-Communist Europe. Baltimore: Johns Hopkins University Press, 1996.

MCLEAY, Michael, RADIA, Amar and THOMAS, Ryland. Money in the modern economy: an introduction. In Bank's Monetary Analysis Directorate. Disponível em: <http://www.bankofengland.co.uk/publications/Documents/quarterlybulletin/ 2014/ qb14q1prereleasemoneyintro.pdf >. Acesso em: em 10 abr. 2017.

MEDARD, Jean Franqois. Le rapport de clientele, du phenomene social a l'analyse politique. Revue Française de Science Politique, v. 26, 1978.

MÉSZAROS, István. Para além do Capital. São Paulo: Boitempo Editorial, 2002.

NICHOLS, Philip M. The Neomercantilist Fallacy and the contextual reality of the foreign corrupt practices act. Disponível em: <http://harvardjol.com/wp-content/uploads/2016/02/ HLL108_crop.pdf>. Acesso em: 15 mai. 2017.

NUNES, Edson. A gramática política no Brasil. Rio de Janeiro: Jorge Zahar, 1999.

O'DONNELL, Guillermo. Delegative Democracy. Journal of Democracy 5, nº1, 1994.

O'DONNELL, Guillermo. Disonancias. Críticas Democráticas a la Democracia. Buenos Aires: Prometeo, 2007.

POLÁNYI, Karl. A grande transformação: as origens da nossa época. Rio de Janeiro: Campus, 1980.

PORTA, D. D. Introdução à Ciência Política. Lisboa: Editorial Estampa, 2003.

PRANAB, Bardhan. Corruption and Development: A Review of Issues. Journal of Economic Literature, v. 35. September, 2003.

SCHMIDT, S. W; SCOTT, J. C.; LANDE, C. and GUASTI, L. Friends, Followers and Factions: A Reader in Political Clientelism. Berkeley: University of California Press, 1977.

SCHWARTZMAN, Simon. Bases do Autoritarismo Brasileiro. São Paulo: Campus, 1988.

SOUZA, Ricardo Luiz. Positivismo, Monarquismo, Autoritarismo, Coronelismo, Populismo Reflexões Sobre a Política e História. Curitiba: Juruá, 2010. 
SPALDING, Andrew Brady. Unwitting sanctions: understanding antibribery legislation as economic sanctions against emerging markets. Disponivel em: <http://www.floridalawreview. com/wp-content/uploads/2010/01/Spalding_BOOK.pdf>. Acesso em: 15 mai. 2017.

TEIXEIRA, M. J. \& REVEZ, A. M. Velhos e Novos Actores Políticos. Partidos e Movimentos Sociais. Lisboa: Universidade Aberta, 2005.

TOFFLER, Alvin. The third wave. New York: Bantam Books, 1980.

VIANNA, Luiz Weneck. Weber e interpretação do Brasil. Novos Estudos CEBRAP, São Paulo, v. 53, março de 1999.

WEBER, Max. La institución estatal racional y los partidos políticos y parlamentos modernos (Sociologia del Estado). Economia y Sociedad. México: Fondo de Cultura Economica, 1969.

Recebido em: maio/2017

Aprovado em: dezembro/2017 